hemorrhage spreading from the dilated nodule on the vein. She was then on the eve of departure for Europe. A prolonged rest may be snfficient to bring about a cure, but it appears probable that it will be necessary to close the dilated vein by the careful application of a fine galvano-cautery point.

As regards the cause of this condition developing in what was presumably a previonsly healthy larynx, I believe that it arose throngh the singer singing music which was above her normal register. This she was able to to without apparent effort owing to her possession of a roice of great Hexibility of range. On this point Jobson Horne, in the British Medical Jommal, March 2.5, 190.5, has observations on "The Pathogenesis and Prevention of Loss of Voice in Singers" which to my mind explain how such a condition can he developed.

\title{
THE ETIOLOGY AND TREATMENT OF MYCOSIS OCCURRING IN THE UPPER RESPIRATORY TRACT. ${ }^{1}$
}

\author{
By Dr. John SEndziak (Warsaw).
}

The following are the particular varieties of mycoses met with in the upper respiratory tract:

(1) Mreosis leptothricia, causative agent Leptothrip buecul is ;

(2) Mycosis sarcinica, causative agent a variety of the sarcince;

(3) Actinomycosis, the cansative agent being the actinomyces;

(4) Mycosis aspergillosis, caused by various kinds of aspergillus;

(5) Mycosis mucorinea, produced by certain varieties of mucor. This, according to some authors (Cixglinski, Hewelka, Sendziak, as well as Schmiegelow), causing the so-called "black-tongue";

(6) Mycosis oidiea (soor), caused by the Oillum albicans.

(1) Mroosts LerTotheicr. - Its synonymous terms are mycosis tonsillaris benigna (B. Fraenkel), pharyngo-mycosis leptothricia (Heryng), algosis (Plycosis), faucium leptothricia (Jacobson), and, hinally, hyperkeratosis lacunaris (Siebemmann). In the year 1873 B Fraenkel was the first to draw attention to the hitherto mknown pathological process-the formation on the faucial

'An essay a warded the prize offered hy Dr. H. Holbrook Curtis to be competed for in $1905^{\circ}$ by members of the American Laryngological, Rhinological and otological society. 
tonsils, as well as on the base of the tongue, of white and grey, prominent, and strongly adherent tufts which, being removed with difficulty, soon reappeared. Under the microscope, these tufts were shown to consist of epithelium and micro-organisms (bacilli and cocci); in the second case, observed by the same author in 1880, the examination showed for the most part Leptothrir buccalis. Fraenkel found Bacillus fasciculatus present in this case. The course of this disease, to which the author gave the name "mycosis tonsillaris benigna," is without fever and is chronic.

In the year 1883 Heryng, of Warsaw, made a minute histological and bacteriological examination of six cases. He gave a detailed description of this disorder, which, because of the constant existence in the tufts of Leptothrix buccalis, he called pharyngo-mycosis leptothricia. These tufts are mostly composed of horny, flat epithelium, surrounded by white, small granular masses and threads of the leptothrix ; the latter colour blue with iodine.

Since that time much attention has been given to this pathological process; articles began to appear in all the countries of Europe as well as in America, where the greatest interest was manifested in this disease, one third of all the papers published appearing in America. French, German, and English literature is replete with papers on the subject, but in Denmark, Sweden, and Norway there has been very little written, which can only be explained by the lack of suitable material in those countries.

Besides the articles mentioned by Fraenkel and Heryng; Siebenmann of Basle, published the results of a minute histological and bacteriological investigation from which he arrived at a conclusion different from that of either Fraenkel or Heryng. He held that the essence of this process consisted in a cornification of the lacunar epithelium; hence his definition of the process"hyperkeratosis lacunaris."

The etiology of mycosis leptothricia has not been positively decided. There exist two principal theories, $(a)$ the parasitic, and $(b)$ the chemical theory. The parasitic theory has the greatest number of supporters. According to this theory the ordinary inhabitant of the oral cavity-the Leptothriv buccalis - is the causative agent of this pathological process. As already mentioned, both Fraenkel and Heryng found this organism in this disorder. Alone or in great preponderance over other organisms present, this agent was found by the following: Semon, Wingrave, Kinny, Gray, Santalo, Provost, Ruault, Nabias, Sabrazés, Ferré, Krakenberger, Chiari, Jacobson, and others. 
Some authorities (Hemenway, Range), while not denying the parasitical origin of mycosis leptothricia, do not regard the Leptothrir bucealis as the causative agent. They hold that other microorganisms found normally in the oral cavity also can produce this type of mycosis (Parser, Tidswell). In justification of their opinion they cite the fact that Leptothrie buccalis is often found on the gums in the neighbourhood of carious teeth, a condition in which we do not usually meet with mycosis leptothricia (Hemenway). Chiari, basing his opinion on the observation that there exists only an increase in the number of Leptothrix buccalis present, does not regard mycosis leptothricia as an independent pathological process.

It was Kyle, an American, who, basing his opinion on very minute bacteriological investigations in the year 1891, became convinced that in this disorder the micro-organisms act a secondary part, their action principally consisting in causing a chemical reaction in the tissues and secretions. The non-parasitic origin of this disease was also held by Hicguet and previous to him by Toeplitz. The claim for priority of the chemical theory, however, belongs to Siebenmann, who in the year 1895 observed and made a histological and bacteriological study of six cases, and gave out the basis of the chemical theory, endeavouring to limit the rote of the Leptothrid buccalis in the disorder to that of a simple "saprophyte." As the principal feature of this disorder he regards the exceedingly well marked cornification of the lacunar epithelium; he noted under the microscope the existence of corneous epithelium without nuclei, and which protruded in shape like a corneous thorn. These thorns have a central excavation filled with detritus, mucus, and micro-organisms. The parts of such thorns which frotude from the crypts of the tonsils are covered on their external surface-with a network of leptothrix.

Referring to the process described above, this author proposes to change the term hitherto used-"mycosis Ieptothricia"-for another more suitable, viz., "hyperkeratosis lacunaris," regarding the latter as a pathological process analogous to that known as pachydermia of the larynx, leucoplakia of the oral cavity, and to a certain extent comparing it to the so-called "black tongue." In regard to the last-named disease, however, opinions are also divided, as we shall see later.

Siebenmann's theory did not find many adherents; but Kraus (Vienna), Lincoln, Friedland, Richardson (America), and Hall (London) are among those who hold a similar view. 
Kyle maintains that we must distinguish two pathological forms-one which we regard as mycosis leptothricia, being simply keratosis, in which condition he disagrees with Siebenmann as to the localisation of the pathological process in the crypts of the tonsils, and consequently, in his opinion the definition "hyperkeratosis lacunaris" is inapplicable; and secondly, a form of typical mycosis leptothricia, i.e. a disease depending on the presence of Leptothrix buccalis. Kyle also holds that there exists cases of mycosis leptothricia without the participation of the Leptothrix buccalis. However that may be, in many typical cases of keratosis we do meet with this micro-organism.

The greatest number of authorities, and among these I number myself, are of the opinion that we are dealing with a typical mycosis caused by the Leptothrix bucculis.

In reference to the term "Leptothric buccalis," which was introduced to medical science for the first time by Robin, according to Miller, the author of an excellent monograph on the microorganisms of the oral cavity, we must understand the constant inhabitant of the buccal cavity to be Leptothrid innominata, Bacillus maximus buccalis, Spirillum sputigenum, and Spirochate dentium. Of these the most important is the Bacillus maximus buccalis, which Kraus claims to be identical with the Leptothric buccalis of Robin.

This organism presents itself in the shape of bundles composed of parallel threads, which stain a blue-violet in a solution of iodine dissolved in potassium iodide. In the soft white sediment on the teeth one finds Leptothrix innominata as well as Leptothrix maxima buccalis, and a similar organism-the Bacillus maximus buccalis, which stains yellow in iodine. The iodococcus raginatus appear usually in small chains composed of four to eight cells sticking on the integument, and stains as follows: the cells become bluishviolet, the capsules slightly yellow. There has been no success in obtaining pure cultures of Leptothrix buccalis, although Jacobson maintains that in three fourths of his cases he seemed to obtain the culture from the tufts situated in the crypts of the tonsils.

Great development of this inhabitant of the oral cavity seems to favour fermentation in the mouth, as well as to cause acidity of the saliva (Fraenkel); it predisposes to caries of the teeth (Kyle), and may aid in predisposing to gastric trouble (Donnellan, Richardson).

Mycosis leptothricia of the upper respiratory tract is by no means as rare a disease as was formerly supposed, but is rather of 
frequent occurrence. The literature to date places some hundred cases on record, which for the period of time, a little more than thirty years-i.e. from the first description of this disorder-is proof enough of its comparative frequency.

I observed mycosis leptothricia 42 times in about 20,000 patients, that is, once in every 500 patients. Krakenberger met with the disease much more frequently, namely, 11 times in 579 patients; on the other hand, Professor Jurasz (Heidelberg) observed it only 3 times among 4000 patients. What is the cause of this difference in the statistics? I am of the opinion that the reason for this lies in the fact that Jurasz's material came from the polyclinic, i.e. from among the poor, who were undoubtedly less liable to become afflicted with mycosis leptothricia. My material is composed of ambulatory (16 cases) as well as private practice (26 cases from among the general number of 10,000 patients), while Krakenberger's (ases are mostly from his private practice.

Mycosis leptothricia is relatively more frequent in females than in males; 24 to 18 was the ratio in my cases. Other authorities (Kraus, Rosenberg, Phillips) have made similar obserrations. Heryng had 8 cases in females and 6 cases in males.

The ages of my patients who were afflicted with this disorder were as follows :

Between 10 and 15 years there were 5 cases.

$\begin{array}{lrlrllll}, & 15 & , & 20 & , & , & 11 & , \\ , & 20 & , & 30 & , & , & 13 & , \\ , & 30 & , & 40 & , & , & 10 & , \\ , & 40 & , & 50 & , & , & 2 & , \\ , & 50 & , & 60 & , & , & 1 & ,\end{array}$

The above figures show that mycosis leptothricia occurs in the respiratory tract, mostly in adults, especially between the ages of 15 and 40 years. Thirty-four cases, almost four fifths of all, occurred in these ages; before 10 and after 40 and 50 years of age its occurrence is very rare. There are only two cases on record below the age of 2 years; the age of Dubler's patient was 8 months.

In reference to the influence of occupation, my cases present the following: Of 24 females, 15 were unmarried, 7 married, and 2 were widows; of the 15 ummarried, 9 were pupils and 1 was a governess; of 18 males there were 4 schoolboys and 2 students, besides 4 landed proprietors, 1 engineer, 1 cashier, 1 civil officer, 1 pensioner, 1 joiner, 1 watchmaker, 1 cook, and 1 tailor.

The frequent occurrence of mycosis leptothricia in the "school age" of both sexes, markedly so in girls, is striking. That they 
are predisposed to it at this time is likely, although unhygienic conditions as well as overburdening them with work are also of etiological importance. It is more difficult to understand the frequent occurrence of this disorder among landed proprietors who live under conditions which seem least predisposing to the development of this mycosis. In my cases I have noted the frequent occurrence of mycosis leptothricia in the better classes-i.e. in private practice.

W. C. Phillips made the peculiar observation that this disease occurs especially in young women very fond of pets such as dogs, cats, and horses, and H. H. Curtis observed that almost every one of his patients had been accustomed to eat raw apples, which very often had been licked by such animal pets. In Myles' cases keratoid spots developed suddenly during an exclusive milk diet.

Undoubtedly one must reckon among the predisposing causes of this disorder bad health (Semon), although, as I have mentioned before, healthy people are not free from this mycosis. In five of my cases-young girls-there were distinct symptoms of anæmia, and in one case the patient had a typical chlorosis. Rosenberg observed the disease in a pregnant woman. Further, I noted in one of my cases-a female, aged thirty-three-symptoms of tubercular affection of the lungs. Richardson's observations show the presence of more or less pronounced gastro-intestinal disturbances. The predisposing causes of this disorder may be summed up in saying that a diathesis to this disease has been noted (Root), that any catarrhal affection of the upper respiratory tract and the acute infectious diseases play some predisposing rôle-Glasgow having noted the disease as following influenzabut the abuse of alcohol and tobacco does not play an important part as a predisposing agent. I only noted the abuse of tobacco in two of my cases.

The localisation of mycosis leptothricia in the upper respiratory tract--According to Siebenmann's theory, i.e. of keratosis, the oral portions of the pharynx, especially the faucial tonsils and their crypts, are the seat of the lesion. Hemenway even proposes the term "mycosis tonsillaris." I do not support this proposition. There can be no doubt that mycosis leptothricia can embrace any part or all of the upper respiratory tract, extending from the naso-pharyngeal cavity (Garel, Labit), affecting for the most part Luschka's tonsil, extending even to the ostia-pharyngea tuborum (M. Schmidt), and finally involving the fossa of Rosenmueller (Law), and ending at the larynx, or at the laryngeal surface of the 
epiglottis (M. Schmidt, Grant). The disease has been observed at the ligament aryepiglottis (Dubler). Root has seen it at the sinus pyriformus. The vocal cords have also been affected (Price-Brown), and even that portion of the larynx below the cords has been the seat of the disorder (Cobb, Dubler).

tll these cases speak against Siebenmann's theory. On the other hand, it is mquestionably true that the most frequent seat uf mycosis leptothricia is at the faucial tonsils. In my cases these were affected fifteen times-the left one eight times and the right tive times; in the remaining two cases both tonsils were equally affected; the left tonsil alone was affected three times, the right alone only once. In a relatively larger number of cases the tonsils and the base of the tongue, i.e. the lingual tonsil, were the seat of mycosis leptothrix; this occurred thirteen times. Both Fraenkel and Kraus believe this region the most frequent seat of the disorder. Heryng saw the affection of the tonsils alone seven times, and seven times he observed the disease also involving the base of the tongue.

The disease is principally situated in the crypts of the tonsilsexceptionally, howerer, as seen in one of my cases; the principal seat of the lesion is the lingual tonsil at the base of the tongue. I saw the lesion on the lingual tonsil alone in three cases. Rarely both faucial tonsil and pharyngeal tonsil are affected simultaneously; this occurred in only one of my cases. I saw the whole pharyngeal ring involved only once. In two cases the faucial tonsils, the pharyngeal walls which were covered with granulations, the lateral folds behind the posterior arches, were affected. Once the faucial tonsils, the base of the tongue, the lingual tonsil, and the pharynx were the seat of the lesion; and, finally, in one case the faucial and lingual tonsils as well as the laryngeal surface of the epiglottis were affected.

Summing up, there can exist the most varied combinations as to the localisation of the lesion. The rare case observed by Curtis, wherein the extension of the mycosis went through the nasal ducts to the eye, besides involving the pharynx and larynx, is a case in point. Once I observed laryngeal involvement alone-typical tufts on the vocal cords-and Grey saw the region of the arytenoid cartilage involved, the corresponding vocal cord being immobile. In Price-Brown's case the affection coated the ventricular bands, and in Cobb's case the vocal cords and the lower part of the larynx were the seats of the lesion.

Clinical picture.-Mycosis leptothricia in the upper respiratory tract shows itself in the form of more or less numerous, pearly- 
white, hard tufts or spots which are situated in the crypts of the faucial tonsil, the lingual tonsil, and sometimes seen on the follicles of the posterior pharyngeal wall. These tufts are characterised above all by a corneous consistency having the appearance of thorns, or, as described by Schmidt, of stalactites, or by Toeplitz as condylomata. They are further characterised by their exceedingly strong adherence to the adjacent tissues, their removal being attended with great difficulty and followed by abundant hæmorrhage. The tissues surrounding them may be entirely normal or in a state of catarrhal inflammation. It is a debatable question whether this latter condition has or has not a causal relationship with Leptothrix buccalis (M. Schmidt).

These tufts, as a rule, form themselves slowly, without inflammatory symptoms, although exceptionally they do occur in more acute forms (mycosis leptothricia acuta or angina leptothricia). Of the last named disorder, cases were described by Santaboand, Dubler (a case of a child, aged eight months, followed by death) ; Ruault, Spaans, and Unterholzner, each observed three cases. Personally I saw four cases of leptothricia acuta.

The course of the disease.-The course of the disease is generally slow. It may last weeks, months, and even years. Generally during the latter periods the tufts begin to show ramifications. Their removal is then easier (Parker). The processes may cease spontaneously. Ordinarily, however, mycosis leptothricia is characterised by great resistance to treatment and relapses are frequent. even after the most energetic attempts at complete removal of the organisms.

Symptoms.-Mycosis leptothricia may occur in the upper respiritory tract without giving any symptoms of its presence. Patients come for consultation anxious because of "white spots" on their tonsils, or the physician only accidentally discovers the spots when looking for some other disease (Michelson, Root). I personally had occasion to see such cases. Occasionally this disorder gives rise to a train of symptoms, as, for instance, scratching and pricking, burning, stiffness, fulness in the throat, disagreeable taste (Root), and pain in the throat (Ingals). In most of my cases there existed a sensation of a foreign body (the so-called paræsthesia pharyngis), twice I observed fotor ex ore, and in three of Ingal's cases there were symptoms of dyspepsia; this was also the disturbing symptom in Richardson's cases. Naturally in the acute forms of mycosis leptothricia there may exist dysphagia, fever, and enlarged lymphatic glands of the neck (Spaan, Unterholzner). 
Diagnosis.-The diagnosis of mycosis leptothricia generally does not present any difficulties, thanks to its highly characteristic signs, namely the appearance and consistence of these corneous tufts situated in the crrpts of the tonsils, so that even without the microscope the diagnosis is possible (Kraus). In all my cases I was able to make this diagnosis i priori, after which I proved its correctness by the microscope. As to the differential diagnosis, the condition most similar to my cosis leptothricia is "tonsillaris caseosa," and this differs from it in the consistency of the tufts; here they are soft and easily removed, and are localised to the tonsillar crypts, while mycosis leptothricia may occur, as already shown, in any part of the upper respiratory tract except the nasal cavities.

The microscope should solve all doubt as to mycosis leptothricia, the tufts being composed entirely of the characteristic threads. For a rapid examination, Siefert and Kahn advise that the masses be rubbed on an objective glass, acidified with a few drops of lactic acid, and then coloured with 1 to 2 drops of a solution of iodine in iodide of potassium. The large bundles and heads of the Leptothrice buccalis will show themselves coloured blue.

In cases of caseous tonsillitis we neet with various organisms from the oral cavity, among which, however, there may also be the Leptothice buccalis, but then this organism is present in small numbers; besides as caseous tonsillitis is the result of a desquamative inflammatory process, the tufts will be composed of corneous epithelium, mucus, leucocytes, and particles of food, etc. In $m y$ opinion, a certain number of cases of caseous tonsillitis, if examined minutely under the microscope, will turn out to be real mycosis leptothricia. This took place in one of my cases. A patient, a female, aged thirty-three, came to me with soft tufts in the crypts of both tonsils; the diagnosis of tonsillaris caseosa was made, but under the microscope Leptothrix luccalis was found to be the true condition present.

Of the acute inflammatory processes, the condition most simulating mycosis leptothricia is the angina tonsillaris follicularis, in which, however, the high fever as well as the swelling of the lymphatic glands of the neck is distinctive. Less similar is diphtheria; here we do not have to deal with tufts and spots, but with a membrane. At any rate, diphtheria sometimes simulates this disorder, and a proper diagnosis can only be made through the use of the microscope.

Prognosis.-The prognosis of mycosis leptothricia of the upper respiratory tract is in general a favourable one. Spontaneous re- 
covery is possible (Semon); it took place in one of my cases. Relatively the prognosis is not so favourable. Mycosis leptothricia is a very obstinate disease and relapses are common. In literature there is recorded only one death-Dubler's case, a child, aged eight months.

Treatment.-Some authorities, among whom are Semon, Schmidt, Richardson, and Kraus, are of the opinion that in cases without subjective srmptoms local treatment is superfluous, the more so as spontaneous recovery is a possibility. Where the general health is bad, treatment should be applied to remedy this-tonics, change of air, sea voyages, etc. (Semon, Wilson). In cases where such exist, correction of disturbances of the gastro-intestinal tract are indicated (Richardson). The greater number of authorities-and to their opinion I adhere-believe that local treatment should be undertaken, and that it should be of a most energetic nature in order to avoid relapses.

Besides gargles of bichloride, $1: 2000$, and as strong as $1: 1000$ (Chiari), $1: 500$ (Parser), and even as strong as $\frac{1}{2}$ to 2 per cent. (Puterman), 5 per cent. chloride of zinc has been used by Nabais and Sabrasis; silver nitrate 1-25 per cent. has been used by Powers and Tuttle; salicylic acid 1:4, in alcohol, has been employed by Tilly; absolute alcohol is the recommendation of B. Fraenkel and Baber; pyoktanin 10 per cent. is recommended by Curtis and Lincoln; formalin, 10 per cent. solution, has been employed by Lederman; tincture of iodine by Grant; nicotine in a proportion of $0 \cdot 2$ : 100 by Jurasz, in one of my cases I had good results from the use of this drug. Chromic acid is recommender by Griffin, Prevost, and Wagner, and finally trichloracetic acid alone or after the application of the galvano-cautery is recommended, a procedure which has given me the best results. Stern and Arnsperger recommend a radical method of treatment, namely, that of curetting the tufts with a sharp spoon. Root follows this with the galvano-cautery. The best method is to puncture the crypts with a sharp cautery. This last-named method has many adherents, among whom are Heryng, Deckert, Siefert, Hemenway, Thomas, Cheatham, Hamilton, Kenny, Wartham, Price-Brown, Hall, Phillips, and myself. Pooley recommends free slitting up of the canaliculi and curetting them in cases where the leptothrix is situated in the canaliculi of the tonsils.

The adversaries of the galvano-cautery number Spicer, Ortuszewsky, and especially Semon, the latter of whom, after having cauterised mycosis situated on the base of the tongue, 
observed parotitis take place with high fever $\left(40^{\circ} \mathrm{C}\right.$.). In one of my cases I had disagreeable complications after the use of the cautery on the lingual tonsil-high fever and great prostration. This occurred in a woman aged twenty-five.

It must be understood that wherever there exists a marked hypertrophy of the tonsil it should be extirpated; and this is best done by means of the galvano-cautery snare, in order to avoid secondary bleeding.

Finally, I must note the farourable influence of tobaccosmoking upon the course of mycosis leptothricia, which was observed by Jurasz, Donnellan, M. Schmidt, Collin, and finally by myself, in a patient, aged thirty years, who, after having commenced to smoke, remarked after a little while that all the tufts on his tonsils disappeared entirely without any other treatment. Of this observation I am sure. We must not forget, howerer, that tobacco is a two-edged remedy, and as such ought not to be recommended (M. Schmidt).

(2) Mrcosis Sarcinica. - This disease occurs in the upper respiratory tract on the mucous membrane of the oral cavity in persons who suffer from disease of the lungs, pneumonia, bronchiectasis, gangrene, and especially in persons suffering from tuberculosis or typhus. It occurs in patients having any catarrhal trouble of the mucous membrane of the oral cavity-stomatitis; it is present in marasmic patients, and it may occur in healthy persous.

From the oral cavity and the pharynx the mycosis may extend to the lungs as well as to the stomach, where the parasite Sarcina rentriculi was discovered for the first time by Goodsir in 1842 . Sarcina enters the upper respiratory tract from the air, where it is present in various forms. In the lungs we find the colonrless form, whilst in the oral cavity its most frequent form is the yellowgreen type.

This parasite is found on the mucous membrane of the tongue as well as on the soft palate (Fisher, Friedreich) in whitish diffuse masses similar to mould (soor). Under the microscope they present themselves as colourless or yellow-brown round or small oral cells, 2-5 $\mu$. in diameter, which are chained one to the other. They form small hexagonal figures, rounded at the angles and sometimes arranged in large patches.

Recent investigation has shown that we are not dealing with a distinct type of sarcina in any one condition, but that all or any kind which are found in the external air may occur in the bolly. 
Mycosis sarcinia has no particular importance. General symptoms are lacking. On the whole, little has been written on this question, and we must refer those interested to Fisher's paper.

(3) Acrinomycosis. - The parasite is the actinomyces. The cause of this pathological process was discovered in the rear 1845 by Langenbeck, and in the year 1877 Bollinger discovered it in horned cattle, among which the disease is most common. To Professor Israel, however, belongs the honour of having first definitely described this parasite as a substantial pathological process in man. Some authorities (Niesse, Hesse) maintain that actinomycosis depends on other parasites, among which is the Cladothix liquefariens (Hesse), yet Wolff and Israel, as well as Ponfick and Bostrom - the most authoritative investigators of this disease-do not agree with this opinion. The subject of actinomycosis of the upper respiratory tract is corered by many papers, the greater number of which were published in Austria, Germany, France, and Sweden. The parasite is usually transferred indirectly to man, exceptionally it is transplanted directly from cattle. Bardez observed a case wherein infection took place from the mouth of a man to the mucous membrane of a clild by means of a kiss. This author believes that flies are also a possible medium of infection.

Actinomycosis is primarily located in the oral cavity, on the alveolar process of the lower jaw (Mikulicz), causing periostitis alveolaris. It rarely spreads through carious teeth to cause actinomycosis of the lower jaw itself. Rarely a primary pyorrhœa alveolaris is present. When we see the patient there is usually the growth or abscess on the lower jaw, and sometimes fistula, from which a slight amount of secretion exudes.

On the summit of the tongue the growth is very hard, and strongly circumscribed. That it is sometimes localised there is evilenced by the cases of Flackner, Bargez, Fisher, Mayer, Hochenogg, Albert, and finally, by Bonnet, who in his Dissertation in the year 1896 cited five cases of this kind, finding the mucous membrane of the cheek also affected in the neighbourhoor of Steno's duct (Partsch). The growth on the tongue, in size equal to that of a pea, shows a slight predisposition to destruction.

From the oral cavity actinomycosis may extend to the pharynx, producing great swelling in the palato-pharyngeal region, with white yellow nodules, identical in appearance to follicular abscess. Retropharyngeal abscess caused by actinomycosis was observed by Schlinge. It seems to avoid affecting the faucial tonsils. Butlin, the author of the best monograph on diseases of the tongue, fails 
to mention any case of actinomycosis of the tonsils. More recently, howerer, Cheatle, Emery, Wright, Therenet, Ruge, Mikulicz, Didsbury, and Bonnet wonld seem to deny this observation in which Isreal originally concurred.

Further, actinomycosis may spread to the larynx, affecting the arrtanoid cartilages and the cords, and extending to the posterior mediastinum (II undler. The involvement of the larynx may also take place by extension of the pathological process from the external portion of the neck to the thrroid cartilage (cases of Henrici, Kuchier, Berard, Lubliner, and Mundler). I observed such a case in a patient aged fifty-three years.

Primary actinomycosis of the cosophagus was seen by Garde (six (ases) : its appearance in the cesophagus, as a secondary process, Wats reported by Abbé.

In general, actinomycosis of the upper respiratory tract belongs to the rare diseases. There are published in the literature some 200 cases in point. In some conntries it seems to be almost epidemic, namely in Anstria and Germany, where about half of all recorded cases occurred.

The disease is twice as frequent in men as in women, which is explained by their occupations bringing them more often in contact with cattle than do the occupations of women. It affects those hetween ten and forty years of age; below ten and above forty the diserase is very rare. I had one case-a landed proprietor-who was fifty-three years of age.

The course of actinomycosis in general is chronic, rarely subat:nte, and exceptionally acute with purulent symptoms (Roosa, Kupper). On account of secondary infection with purulent microuraunisms, lymphatic involvement may be produced (Cheatle, Emery).

The symptoms of actinomycosis of the upper respiratory tract consist in general of very violent pains in the region of the patholngical process - in carions teeth; in neuralgic pains on the corresymding sile of the face, although some anthorities (Wright) give as a characteristic the complete absence of pain. In acute cases there are present fever, chills, and attacks of suffocation and pain during the act of swallowing (Kupper).

The diagnosis of actinomycosis should not be difficult except in the earlier stages, where the condition presents nodular infiltrations, and then the disease is apt to be mistaken for malignant neoplasms (carcinoma). The chronic course, the great induration of surrounding parts, the slight excretion from the fistulous opening, the 
localisation of the trouble to the face and neck (Illich), and, finally, the escape of the lymphatic glands-all these points help in a certain degree to make the diagnosis. When the abscess is already formed, then the diagnosis is easy, because of the characteristics visible to the naked eye. The pus contains suspended in it the yellow grains which under the microscope, after colouring with iodide of potassium, show the radiant structures with mace-like ends of the actinomyces. They also colour well by Gram's method, or, better still, its modification-i.e. with the addition of carmine (Gram-Günther), the threads colouring themselves bluish-black, the butts red.

Relative to the differential diagnosis, we must take under consideration the following pathological processes: gummata which are undergoing destruction, carcinoma of the œsophagus, tubercular growths especially, chronic abscess of the tongue, suppurating cysts, and, finally, cysts. In all these processes, however, the clinical picture, the history, the examination of the lymphatic glands of the neck, and the microscopic examination will clear up the question of differential diagnosis absolutely.

Generally speaking, the prognosis of actinomycosis is not favourable, and this is especially true where the internal organs have become affected by metastatic processes, which may occur either in the brain, pleura, kidneys, liver, heart, lungs, etc. (Hesse). 'The prognosis is worse in cases of the lower jaw, larynx, and œsophagus, where there is inclination for its extension to the mediastinum. In cases of actinomycosis of the base of the tongue where the process is circumscribed and therefore operable, the prognosis is more favourable. I may note in passing that in one of my cases of actinomycosis of the larynx the paralysis of the recurrent nerve of the corresponding side followed.

The treatment of actinomycosis occurring in the upper respiratory tract is primarily surgical in nature. Careful curetting, or excision of the affected tissue is called for. Some authorities recommend the application of a 5 per cent. solution of carbolic acid, and 1:1000 bichloride (Korff); the application of $\frac{1}{2}$ to 1 per. cent. methyl violet is recommended by Raafe, and nitrate of silver fused on a sound and introduced into the fistulous opening is used by Koettaitz. Finally, there are many adherents to the administration of potassium iodide internally, by which they seem to obtain recovery without operation. Among those who employ this method of treatment are Lissa, Claisse, Berard, and Heryng.

Besides the mycoses occurring in the upper respiratory tract 
already described, viz. mycosis leptothricia, mycosis sarcinica, and actinomycosis, we meet with various kinds of moulds, the principal ones of which are classed under the hyphomycetes-aspergillus, mucor, and the oidium, and finally the rarer form, the penicillium. In the botanical sense these differ only from each other by the method in which they form their spores-as, for example, the mucor, where the fruit-carrying threads arise from the entangled mycelium bearing a little bag (the sporangeium); in it are the spores (conidia); while in the aspergillus the fruit-carrying thread is thickened in the form of a mace to whose surface small "sterigmata" adhere, carrying the spores; in the oidium variety the spores adhere directly to the fruit-carrying thread; and finally, in the penicillium the fruit-carrying thread has ramifications very similar to small pencils, on which the spores are formed.

Among the various kinds of aspergillus and mucor observed in the respiratory tract there have been found Aspergillus fumigatus; glaucus, and nigrewcens, as well as Mucor corymbifer and niger, the latter of which is the cause of the "black tongue" (Cixglinski, Hewelke) ; finally, penicillium glaucum is also found. The most important of all the pathological mould parasites found is the Oillium albicans, the Oidium lactis (Robin), the cause of "soor" (French muguet, English thrush). To this class certain varieties of yeasts also belong (blasto-saccharomyces), as was demonstrated by the more recent investigations of Busse, Robinowicz, and especially by San Felice.

The best method of examining these moulds under the microscope is as follows: A small quantity of the material is put in a drop of glycerine on an object glass and divided into very small particles by means of needles. It is then covered and examined with a strong dry lens. Colouring of the specimen is unnecessary unless examined in tissues, when the method recommended by Weigert should be followed out. The above-named moulds develop best at body temperature; they grow best on sterilised bread cultures. Recent observations have shown that aspergillus and oidium are not substantial forms. The aspergillus is only a form of fruit-carrying variety of the eurotium, while oidium is the conidial form of erysiphe. The last named, as well as the "eurotium," belong to the "ascomycetes."

(4) Mrcosis Aspergillina.-This variety of mycosis in the upper respiratory tract is rarely seen. The cause of this undoubtedly is due to the peculiarity of these regions. For example, in the nasal cavity the obstacle to the development of this parasite is the con- 
stant current of air passing through the nares (Deile), as well as the constant bathing of the nasal mucous membrane in its natural secretions; furthermore, the existence of purulent micro-organisms (cocci) are inimical to the development of these parasites, and finally, the temperature of the body is not a suitable one. In the pharynx, however, a poor development of the aspergillus takes place on the mucous membrane covered with mucus; it also occurs on ulcerated surfaces where the secretions are fotid (Siebenmann).

Persons working in tanneries, or those dealing in leather, are predisposed to this disease, as leather is an excellent medium in which the development of the aspergillus grows. In general this parasite occurs as a saprophyte, and is a habitant of living mucous membrane. In the upper respiratory tract we meet with three varieties of Aspergillus - fumigatus (the most frequent type), glaucus, and nigrescens.

There are only eight publications on record, from which I quote the following:

(1) The case of Dunn, of Richmond, who, two weeks after the cauterisation of the nasal septum with chloroform, found a scab covered with brown-yellowish substance looking like fruit-jam, which under the microscope proved to be Aspergillus glaucus.

(2) Case of Delic, of Leipsic, who found on autopsy Aspergillus. fumigatus in both nasal cavities in a case of ozæna.

(3) The case of Mackenzie, of Baltimore, where, in a patient suffering with empyema of the antrum of Highmore, the patient expelled some of the membrane of the sinus on which there was found (under the microscope) Aspergillus fumigatus.

(4) Zarkino's case: This was a case analogous to the abovea woman, aged fifty, with empyema of the antrum of Highmore; the findings were Aspergillus fumigatus.

(5) Schubert's case: A badly nourished woman, aged seventyfive, whose naso-pharyngeal cavity was filled with a dark browngreen mass appearing clay-grey externally, with symptoms of total nasal obstruction, and who expelled a cast from the nose and nasopharynx which under the microscope showed the external layer to be composed of degenerated mucous corpuscles and flat epithelium, while centrally the mass gave evidence of the presence of Aspergillus fumigatus.

(6) Siebenmann's case, wherein the fold of the pharynx of an old woman was covered with scabs which were composed mostly of Aspergillus fumigatus and Aspergillus sidulans, as well as Mucor corymbifer. 
(7) Dick's case, a young healthy man who showed between the arches of the fancial tonsils tufts of corneous substance of a blackish colour, which under the microscope proved to be Aspergillus nigresceis.

I must note in passing that (tuarnacia, of Catania (Sicily), observed three cases of otomycosis aspergillus (cause, Aspergillus niger) which were cured by the use of hydrogen peroxide, with 20 per cent. oxygen.

II. Schmidt observed Axpergillus fumigatus as well as glaucens in the nose of a case with atrophic rhinitis.

(.) Mrcosis Mrcorina.-Mycosis mucorina in the upper respiratory tract occurs rarely. It appears in two forms-(1) mycosis dependent on the Mucor corymbifer, and (2) mycosis depending on the Muco niger, the more usual form.

The first form was observed by Paltauf, of Vienna. A patient, aged fifty-two, was suffering from enteritis and peritonsillitis circumscripta, with fever, cough, and swelling of the spleen; the patient had icterus, as well as affections of the sensorium. After fourteen days death took place, and the autopsy revealed, among wther things, phlegmon of the pharynx and larynx, which, microscopically, was found to be caused by Mucor corymbifer. The case of Siebenmann, mentioned above, also belongs to this category.

The second form-mycosis mucorina nigra-occurs oftener, according to Cixglinski, Hewelke, Sendziak, and Schmiegelow. It forms the essence of the so-called "black tongue." We understand by this term the pathological process characterised by the appearance in the superior surface of the tongue in the neighbourhood of its hase, in front of the papilla circumvallatæ, of more or less extended discoloration-generally black, sometimes brown (Sendziak), or even yellow (Dinkle), of an irregular oval form, or triangular, with an even, or more frequently an uneven, hairy surface. The process may be acute, lasting a few days, or it may be chronic, lasting months, and even years.

The disease is not as rare as it was formerly supposed, and we meet with it now quite frequently in literature. There are about fifty articles on the subject, the greater number of which are English; then come the French and the German. Personally, I lave seen four typical cases of "black tongue."

The English writers on this subject include Stocker, Breatch, Bryden, Barnes, Balfour, Graham, Masters, Smith, Lediard, Lake, Potter, Abercromby, and Semon. In America, Levoiseur, Leheac, Maraval, Goodale, and Johnson have written; in France, Villare, 
Surmont, Wollerand, Lannois, Robert, Lecorq, and Weil ; in Germany, Schech, Bernhardt, Brosin, Dinkler ; in Austria, Roth; in Poland, Rydgier, Cixglinski, Hewelke, and Sendziak; in Belgium, Mascine and Parmentier; in Holland, Soll ; in Denmark, Schmiegelow; and finally, in Russia, Gundobin; have all written on the subject.

What is the essence of the "black tongue"? Its etiology is not quite clear. We only know that it occurs more often in men than in women. (All of my four cases were males.) It seems to occur at a more advanced period of life-between the fortieth and seventieth years-although it may occur in children. Gundobin's case was a child, aged one and a half. Of my patients the youngest was aged thirty.

Some authorities (Cixglinski, Hewelke, Sendziak, Roth, Robert, Vollmer, Maraval, and Parmentier) believe this disorder due to the abuse of tobacco, which I noted in all of my four cases. Others (Gundobin and Lehiac) hold that it comes from disturbances of digestion and acidity in the mouth. In one of my cases, a patient aged thirty, the whole body, but especially the breast and shoulders, was covered with abundant hairs. In another of my cases gastric disturbances were noted. In Lediard's case there was present simultaneously with it cancer of the tongue, in Bernhardt's case tabes dorsalis, Vollmer's case stomatitis mercurialis, Sendziak's case myelitis, Masoni's case tuberculosis, Lehiac's case pregnancy, and again, in Sendziak's case, œsophageal spasm. Dinkler observed the occurrence of black tongue following scarlatina.

Etiology.-Most of the authorities, of whom I name Rosenberg, Bresgen, Schech, Brazin, Surmont, Wollerand, Rydygier, Staker, Leviseur, Masoni, Potter, Vollmer, Goodale, Wingrave, Angier, and Johnson, see in the pathological process an hypertrophy of the epithelium of the filliform papillæ with secondary cornification (hyperkeratosis-Bresin, Schech). The dark colour of the tongue seems to depend on the increased corneous pigment in the normal corneous cells, so that the older, harder, and dryer the corneous layer is, the darker the discolorations will be.

Although some authorities, among whom are Schech, Rydgier, Wingrave, etc., found on examination various organisms-leptothrix, cocci, bacilli, etc.-they regard these as of accidental occurrence, having nothing to do with the etiological factor of the pathological process itself. On the other hand, in one of Sendziak's cases, where an autopsy took place, the patho-histological examination of the tongue showed the characteristic traces of "black 
tongue," or more properly, " brown tongue." There were no distinct changes or hypertrophy or keratosis of the filliform papillæ. At any rate, the idea of the parasitic origin of "black tongue" was suggested long ago by some authorities. Dessoix and Soll regarded this disease as a mycosis depending on the so-called glossophytons, the parasite showing itself in the form of small oval globes, strongly refracting the light and giving a dark colour to the papillæ. According to Bresin, who observed the case, they were not fully developed mould parasites-i.e. soor.

Raymond also held to the parasitic origin of the disease. $\mathrm{He}$ found delicate spores, round or oval in form, situated on the filiform papillie. West is also of this opinion. Dinkler found in the sediinent on a black tongue the closely entangled threads with sprouting excrescences, which were sharply pointed. Roth in two cases found very numerons micro-organisms, which he believes depend for their existence on this pathological process. Lake found rounded spores in cases of black tongue, which he regarded also as the cause of this disorder. Butlin also holds the opinion that the trouble is of parasitic origin. With this view Launers agrees, and Gundobin, who saw three cases, found various parasites-leptothrix, Spirocheate buccalis, Oidium albicans, Bacillus subtilis, Staphylococcus albus, etc. Again, Lecocq as well as Leheac found leptothrix and spores similar to trichophyton.

All these observations, however, by no means solve the question of the etiology of "black tongue." None of the above-named ibuthorities have proven his opinion. Only Dinkler made cultures, and these were withont positive results. Cixglinski and Hewelke in the year 1892 cultivated the mould parasite in acute cases of hlack tongue observed by them. The chronic condition they regarded as the result of cornification of the hypertrophied epithelial cells of the filiform papillæ. They found Mucor niger, of a form morphologically identical with Mucor corymbifer, but differing from this in the want of pathogenic properties; hence these authorities propose for the acute type of black tongue another, more scientific, name-" mycosis linguæe nigra s. nigroties mucorina lingue."

Two years later Sendziak, of Warsaw, observed two cases of chronic black tongue. He cultivated Hucor niger, hence he believes in the mycotic origin of the disease.

Finally, in 1895 Schmiegelow also cultivated parasites of the variety known as hyphomycetes (mucorinæ) from two cases of black tongue. They differed a little from the parasites described 
by Cixglinski, Hewelke, and Sendziak ; Schmiegelow supposes that the negative results of the bacteriological examination depend on unsuitably chosen culture media. He thinks the best culture media for this parasite to be a composition of white bread and gelatine kept at a temperature of $21^{\circ} \mathrm{C}$. At $37^{\circ} \mathrm{C}$. this parasite does not grow.

Regarding the etiology of black tongue, it is somewhat analogous to mycosis leptothrix, which, as already shown, is regarded by some (Siebenmann, etc.) as a hyperkeratosis, but by the greater number as caused by the Leptothrix buccalis. I regard black tongue as a mycosis caused by the Mucor niger which I successfully cultivated in two cases.

The course of black tongue is generally acute (Dinkler, Cixglinski, Hewelke, Gundobin); sometimes it runs a chronic course (Sendziak and Gundobin). In all my cases the course was chronic.

The symptoms differ; a bad taste in the mouth (Soll), sensation of a foreign body, salivation, burning, diminution of the mobility of the tongue are the more common symptoms. Sometimes there is an entire absence of symptoms, as was observed in one of my cases.

The diagnosis of black tongue, thanks to the clinical picture of hairy black or brown discoloration on the posterior part of the papillæ circumvallatæ, presents no difficulties.

Of the differential diagnoses, we must think first of all of Addison's disease, in which there were observed by Fowler bluishblack discolorations of the tongue, but here the discolorations were also to be seen in other parts of the oral cavity. One must remember that the application of certain drugs, as well as certain foods, drinks, and also tobacco, may simulate this disease.

The prognosis of black tongue is favourable when the process is not complicated by other serious diseases (Sendziak's case of myelitis).

The treatment of black tongue consists of scraping away the hairy productions, as well as using alkaline gargles. Brushing with a 5 per cent. zinc chloride, the application of hydrogen peroxide, 10 per cent. solution of bichloride of mercury, are all recommended; 5 per cent. salicylic acid, and 10 per cent. resorcin are also used. Semon and Unna have employed 5 per cent. collodium. Abstinence from smoking is also important (Maraval's case, in which after the commencement of smoking the disorder reappeared). In cases where all symptoms are absent, all treatment is superfluous. 
(6) Soor.-(French muguet, English thrush)-that is, mycosis soorina. Since the days of Hippocrates soor was not distinguished from aphthæ. At the end of the eighteenth century this term was first accepted in France as the definition of a distinct pathological process. This is the disease par excellence of childhood; one meets with it mostly in sucklings, especially in the first days and weeks, but it may be found to the end of the second month in artificially nourished children. Uncleanliness of the oral cavity during dentition, the weak constitutions of the children, as well as the nature of their nutrition, favours the development of this pathological process. It is rarer in children over two months of age, although in adults it may occur (Thorner, Sendziak, Gage, Oppenheim, Teisser, Tordens, Scheff, as well as Reubold, who saw fifty cases below one year and only ten times after twenty years of age). I have seen four cases in adults (two females and two males) between the ages of fifteen and seventy. Mettenheimer reports a case of a female between eighty and ninety years of age.

In adults thrush occurs during long and exhausting diseases, as, for instance, tuberculosis-I had one such case-diabetes mellitus, typhus, gastritis alcoholica. I also saw it in a case of heart-disease. Thrush may also occur with parotitis (Damashino). Finally, thrush has been observed in quite healthy men by Schmidt, Schech, Fraenkel, Mlinik, Freudenberg, and Siefert.

As a result of acute pathological processes, thrush occurs less frequently in adults (Forcheimer); Loer described a case of croupous pneumonia, in which, on the seventh day of the disease, during the crisis, thrush was apparent in the oral cavity, from which it extended very rapidly to the pharynx and larynx. Altman observed and described a similar case. I saw a case in a child aged eight months. A very interesting case of thrush, involving the larynx and nares, was observed in a patient aged seventeen years, following an attack of influenza; this case was described by Thorner of Cincinnati; Rosenberg saw a similar case following influenza.

Thrush following diphtheria was seen by Sendziak in a girl aged fifteen. The disease was also seen to follow meningitis, morbilli (Reubold, Sendziak), and scarlatina. I have seen thrush appear on the sixth day after hard instrumental labour. Thrush may occur as an endemic disease in hospitals.

There are many papers on this subject, the majority appearing in France and Germany, but America, Italy, Poland, Holland, and spain also furnish their quota. 
Etiology.-At the time of Robin's writing, thrush was regarded as caused by Oidium albicans-Oidium lactis. At present we believe differently - namely, that it is caused by Mycoderma vini (Grawitz), Saccharomyces albicans (Rees), and Endomyces albicans (Villermin).

According to Plaut, Oidium albicans is identical with Monilia candida; Villermin numbers it with the "ascomycetes" having characteristic spores, and calls it Endomyces albicans. In general the position of this parasite is undecided.

Infection takes place from ingested objects, from nipples, and less frequently from the air, or during the phenomon of parturition.

Pott connects this trouble with epidemic pharyngitis of cows, the infection being carried by means of the air. Klemperer showed that after the injection of pure culture into the veins of a rabbit general mould mycosis appeared. Stoos and Grassed agree with his views.

Thrush localises itself to the oral cavity, the tongue being specially affected (Butlin), principally along its edges and tip ; the papillæ are often prominent as red points here as well as at the base (tonsilla lingualis, Seifert). The frenum is also occasionally affected, while the internal surface of the lips-the angulus oristhe gums, and cheeks are also not free from the lesion. The tonsil is rarely the seat of the lesion, although in my cases these were often affected. From these localities the trouble extends by contiguity of tissue downward to the pharynx and cesophagus (Virchow, Wagner, Schmidt, Langerhans, and Mackenzie). The last-named observed three cases of primary thrush of the cesophagus. Zalesky observed it in the stomach. That it occurs in the larynx, trachea, and bronchi the cases of Schroetter, Massi, Fasane, Sendziak prove. More rarely it extends from the oral cavity upward to the nasopharynx, involving the pharyngeal tonsil (Thorner). It may spread to the ostia tubarum and fossæ Rosenmueller, as shown by the cases of Valentine, as well as by two of my cases.

An opinion existed formerly that thrush only developed on mucous membrane whose covering was of the flat epithelinm variety (Berg, Reubold, Butlin, Solis-Cohen, Jules, Semon), cylindrical epithelium not being considered favourable to the development of this parasite, and in those cases where it did spread it was considered as a simple (accidental) extension without really involving the mucous membrane. Against this belief there are, however, the following facts: the extension of thrush to the mucous membrane of the inferior turbinate bodies, as well as to 
the septum in cases of hereditary cleft palate, and the extension of thrush to the windpipe, covered with cylindrical epithelium. The cases reported by Siebenmann, Sendziak, Thorner, and M. schmidt, where the localisation of thrush was confined to the nose as well as the larynx-the lining membrane of which is cylindrical -also contradict this theory.

Clinical picture.-Thrush occurs as small, white spots, round, with small excavations in the centre, easily removable at first, later, as the disease progresses, more adherent. These spots coalesce irregularly, forming a sort of membrane of a dirty colour, the underlying mucous, membrane being red and swollen. The slighter forms of this disorder last only from one to four days. A severer type exhausts the patient, the whole oral cavity is covered with strongly adherent membrane, which is removable with difficulty, and followed by hæmorrhage.

The underlying mucous membrane, being swollen and red in the acute type-the angina soorica of the French authors-may change to a chronic character, then the mucous membrane loses lustre, becomes bluish, flattened, with thickened papillæ of atrophied epithelium.

Symptoms.-The suckling children fail to get sufficient nutrition on account of the pain; they become restless, breathe with difficulty, push the tongue forward, the power of the voice is weakened, exhaustion supervenes, vomiting takes place, the stools are green, evidencing gastric catarrh. In adults the symptoms are less severe. Massi and Fasane saw symptoms of suffocation from the mould-masses in their cases. Sometimes there is absence of all symptoms (Sendziak), at times simply a burning and dryness in the throat, as well as difficulty in swallowing (Kronenberg).

Oidium albicans is characterised by the existence of small white threads with double lines and transverse divisions (mycelium), ending in bulbs (sporangeia) as well as rounded spores. In the membrane we find detritus and epithelium cells. The sections of tissue sometimes show the penetration of the threads deeper into the submucosa, where there are symptoms of reactionary nature.

Differential diagnoses between thrush and particles of food or component parts of milk are easily made. Between thrush and aphthæ we note that aphthæ are not so round and have not so regular a form. Diphtheria sometimes shows a resemblance (Schadenwald), but the absence of fever, except in cases of soorica angina, will help to clear up the diagnosis. There is also a less compact membrane, and the situation of the membrane itself is of 
no help. From syphilitic plaques it can be differentiated by the concurring skin and lymphatic gland lesions.

Prognosis.-The prognosis is not always favourable, especially in small children, where complications easily occur (gastro-intestinal trouble). General infection is also possible (Hubner). Puercheimer saw paralysis of the osophagus following thrush. In one of my cases death occurred from acute pneumonia.

Treatment.-The best method is to observe a strict prophylaxis, to keep the nipples clean; systemic cleansing of the oral cavity also is very important. Grosz, of Buda Pesth, advises the use of 10 per cent. silver nitrate in the oral cavity the first day after birth. Cleaning the mouth in all cases of intestinal catarrh in children and adults is recommended. General treatment is also important. In many cases local treatment is unnecessary, especially in adults (Sendziak). In children carefully rub the thrush spots with swabs moistened with a weak solution of boric acid. Escherich recommends a swab of cotton containing pulverised boric acid and a little saccharine.

Of other drugs used in this disease are the following : borax, ( 3 to 4 per cent.), chlorate of potash, permanganate of potash 4 per cent. (Schadwald), bicarbonate of soda 5 to 10 per cent., liq. alum. acet. pur. (Saltman), sublimate solution 1:1000 (Kraus), carbolic acid naphthol (Cattaert), and finally drugs mixed with glycerine are recommended by Boinet.

In serious cases brushing with iodide of potassium sublimate solution 1 per cent., silver nitrate 5 per cent., pyotanin 10 per cent., hydrogen peroxide, and finally ferric chloride are recommended.

Where the œsophagus is affected, the internal application of chlorate of potash is indicated. This must be done carefully. Vichy and emetics may also be given, but caution must be observed for fear of paralysis of the heart. Finally rubbing the parts clean by means of cesophageal sponges may be attempted.

As I have already mentioned, according to the latest researches of the Italian school, of whom San Felice is probably the head, the mould parasites (Oidium albicans) belong to a certain degree to the yeast parasites (blasto-saccharomycetes). They rarely occur in man, as a pathogenic agent causing a special kind of mycosis.

The two cases described in French literature belong to this category: (1) Parak's case, where on the fourth day following birth there appeared on the base of the tongue white spots (thrush?), which under the microscope were supposed to show, not 
the Oidium albicans, but a variety of the yeasts: (2) Troisier's and Achaline's cases, which were analogous, clinically with angina soorica in a typhoid patient, but the microscopic examination also gave a variety of yeast similar to that found in beer-dregs.

Finally, there exists in literature some cases of mycosis of the upper respiratory tract which are of uncertain origin and which I report to complete the whole picture of these disorders.

(1) Solis-Cohen's case of mycosis of the pharynx of uncertain origin during the course of rheumatic angina.

(2) Klaman's case, cited by Schech-grey-yellow membrane on the posterior arch as well as on the uvula composed of mycelium and cocci (the threads having mace-like ends).

(3) Hall's case-mycosis fungoides of the pharynx and larynx (arytenoid cartilages), in a patient, aged fifty-two.

(4) Hallspeen and Jeanselmes's case, with autopsy-mycosis fungoides of the left posterior arch, the tonsils, faucial as well as lingual, the aryepiglottic folds, the epiglottis, and the vocal cords.

\title{
DIPHTHERIA IN REFERENCE TO THE INFECTIYITY AND NOTIFICATION OF LATENT FORMS.
}

\author{
By P. Watson Williams, M.D., \\ Physician in Charge of the Throat Department, Bristol Royal Infirmary; \\ Physician for Diseases of the Nose, Throat, and Ear, Bristol \\ Deaf and Dumb Institute.
}

The diagnosis of any iufective illness, apart from its purely scientific interest, is often a matter of great and far-reaching importance in practice, and very frequently the greatest difficulties arise in connection not with the severe, but rather with the slighter attacks. Thus with diphtheria, it is not the well-developed attacks with definite membranous exudation in the fauces or other parts of the upper respiratory tracts, but the latent attacks which are prone to escape recognition, or to give occasion for any doubt as to infectivity or notifiability.

It may be well to state what we mean by "latent" diphtheria. If we may define diphtheria as any pathological condition, local or general, due to infection by specific diphtheria organisms, diphtheria is "latent" when such pathological conditions are unaccompanied by obrious illness. Thus a nasal catarrh, increased pulse frequency, an irritable heart, a redness of the fauces, or slight 